\title{
User and System Considerations for the TCSTEK Software Library
}

\author{
W. H. Gray
}

\section{MASTER}

\section{OAK RIDGE NATIONAL LABORATORY} OPERATED BY UNION CARBIDE CORPORATION - FOR THE DEPARTMENT OF ENERGY 


\section{DISCLAIMER}

This report was prepared as an account of work sponsored by an agency of the United States Government. Neither the United States Government nor any agency Thereof, nor any of their employees, makes any warranty, express or implied, or assumes any legal liability or responsibility for the accuracy, completeness, or usefulness of any information, apparatus, product, or process disclosed, or represents that its use would not infringe privately owned rights. Reference herein to any specific commercial product, process, or service by trade name, trademark, manufacturer, or otherwise does not necessarily constitute or imply its endorsement, recommendation, or favoring by the United States Government or any agency thereof. The views and opinions of authors expressed herein do not necessarily state or reflect those of the United States Government or any agency thereof. 


\section{DISCLAIMER}

Portions of this document may be illegible in electronic image products. Images are produced from the best available original document. 


\section{Printed in the United States of America. Available from}

National Technical Information Service

U.S. Department of Commerce

5285 Port Royal Road, Springfield, Virginia 22161

Price: Printed Copy $\$ 4.50$; Microfiche $\$ 3.00$

This report was prepared as an account of work sponsored by an agency of the United States Government. Neither the United States Government nor any agency thereof, nor any of their employees, contractors, subcontractors, or their employees, makes any warranty, express or implied, nor assumes any legal liability or responsibility for any third party's use or the results of such use of any information, apparatus, product or process disclosed in this report, nor represents that its use by such third party would not infringe privately owned rights. 
ORNL/TM-6918

Dist. Category UC-20

Contract No. W-7405-eng-26

FUSION ENERGY DIVISION

USER AND SYSTEM CONSIDERATIONS FOR THE TCSTEK SOFTWARE LIBRARY

W. H. Gray

Date Published - August 1979

NOTICE This document contains information of a preliminary nature. It is subject to revision or correction and therefore does not represent a final report.

\author{
Prepared by the \\ OAK RIDGE NATIONAL LABORATORY \\ Oak Ridge, Tennessee 37830 \\ operated by \\ UNION CARBIDE CORPORATION \\ for the \\ DEPARTMENT OF ENERGY
}


THIS PAGE

WAS INTENTIONALLY

LEFT BLANK 
CONTENTS

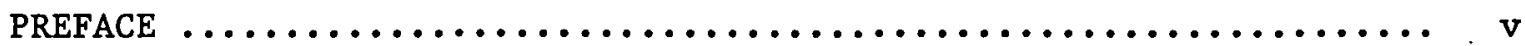

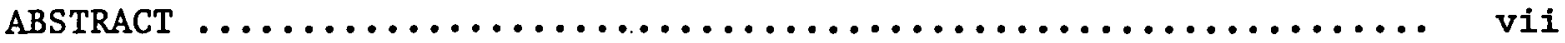

1. INTRODUCTION $\ldots \ldots \ldots \ldots \ldots \ldots \ldots \ldots \ldots \ldots \ldots \ldots \ldots \ldots \ldots \ldots \ldots \ldots \ldots$

2. ACCESSING THE TCSTEK SOFTWARE LIBRARY $\ldots \ldots \ldots \ldots \ldots \ldots \ldots \ldots \ldots$

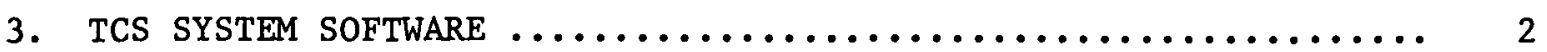

4. TCS CHARACTER MANIPULATION SOFTWARE $\ldots \ldots \ldots \ldots \ldots \ldots \ldots \ldots \ldots \ldots$

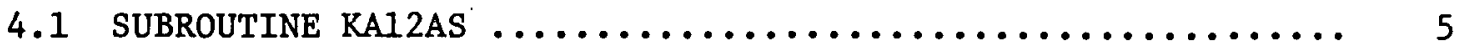

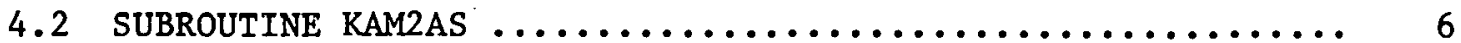

4.3 SUBROUTINE KAS2A1 ........................ 8

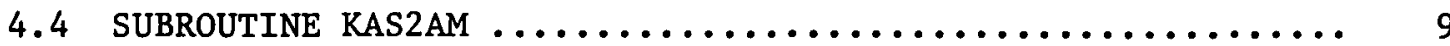

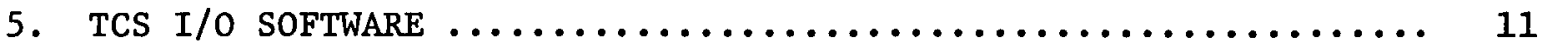

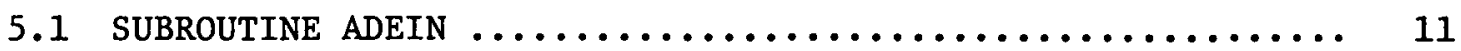

5.1 .1 Further Cons1derations ................... 12

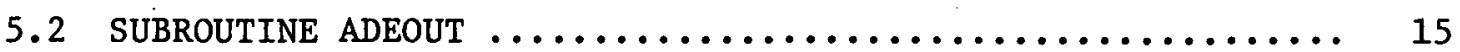

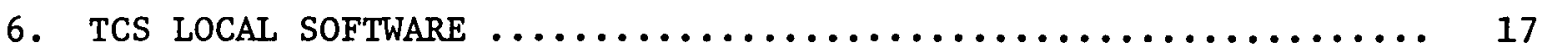

6.1 SUBROUTINE ITRMBD $\ldots \ldots \ldots \ldots \ldots \ldots \ldots \ldots \ldots \ldots \ldots \ldots \ldots \ldots \ldots$

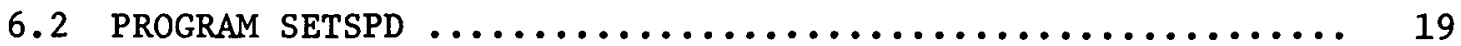

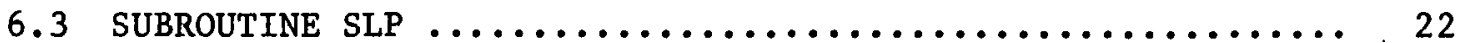

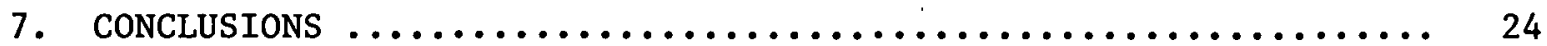

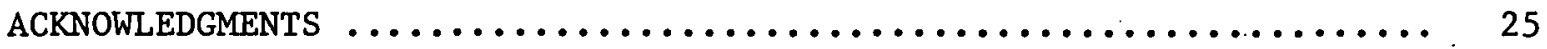

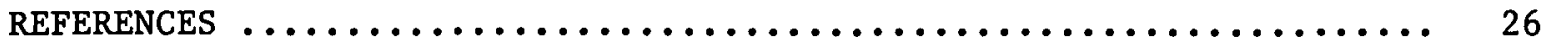




\section{THIS PAGE}

WAS INTENTIONALLY

LEFT BLANK 
PREFACE

This work was sponsored by the ORNL Fusion Energy Division Large Coil Program and was done in conjunction with system development on the GIFTS $4 B^{1}$ structural analysis system. 


\section{THIS PAGE}

WAS INTENTIONALLY

LEFT BLANK 


\begin{abstract}
This report documents the idiosyncrasies of the Tektronix PLOT 10 Terminal Control System level 3.3 software as it currently exists on the ORNL Fusion Energy Division DECsystem-10 computer. It is intended to serve as a reference for future Terminal Control System updates in order that continuity between releases of Terminal: Control System PLOT 10 software may be maintained.
\end{abstract}


1. INTRODUCTION

This report documents the implementation of the Tektronix PLOT 10 Terminal Control System (TCS) software into the Fusion Energy Division (FED) DECsystem-10 computer. This report supersedes all previous reports on this subject and specifically applies to TCS level 3.3 software. TCS level 3.3 documentation may be found in Ref. 2, and a system guide may be found in Ref. 3 .

This report pertains to the software library on REL: called TCSTEK. REL and is divided into the following sections:

a) In Sect. 2 the reader may find out how to access the TCSTEK software library.

b) Section 3 discusses several of the system considerations which prompted the writing of this document.

c) Section 4 presents the locally written character manipulating software for TCS.

d) Section 5 presents the locally written terminal I/0 software for TCS and specifically enumerates its advantages and disadvantages.

e) Section 6 discusses the local modifications to the TCS software - in particular the program which sets the transmit speed code for all teletypes connected to the FED DC10 communications interface and the corresponding subroutine modifications in the TCS source program necessary to access the transmit speed code. If the reader of this report is uninterested in the system implementation of these subroutines, then probably the only section which should be required reading is the description of the subroutine ADEIN (see Sect. 5.1). This subroutine is called every time the user 
requests terminal input through TCS and is of particular interest if the user wishes to use the graphic cross-hair cursor as an input mechanism. Otherwise, all sections of this report are intended for readers who want further information about the locally written system structure of TCS.

\section{ACCESSING THE TCSTEK SOFTWARE LIBRARY}

The TCSTEK library's relocatable object module (.REL file), which for loading efficiency has been indexed by program MAKLIB, may be found on REL:TCSTEK.REL. As a user convenience, an indirect command file (.CMD file) has been created on device PUB: to simplify use of the Tektronix terminal control software. An example of accessing the TCSTEK library follows:

.EXECUTE Yourpg, QPUB:TCSTEK and the TCSTEK software library will be loaded in the library search mode in order that the global external references made by yourpg will be det'ined.

\section{TCS SYSTEM SOFTWARE}

The TCS level 3.3 software has been implemented without any user-discernible differences between it and the vendor-supplied installation instructions, ${ }^{4}$ as it successfully passes the vendor test program. 5 sections 4 and 5 present the six subroutines, KA12AS, KAM2AS, KAS2A1, KAS2AM, ADEIN, and ADEOUT, which are required by TCS in order for it to perform correctly. 
There are two major differences between the TCS software as received and that which is available in relocatable object module form. They are:

a) The call to subroutine IOWAIT has been replaced with a call to subroutine SLP in subroutines HDCOPY, ERASE, and NEWPAG.

b) Subroutine INITT has been modified to attempt to access the transmission speed which is available in the monitor table for any teletype line number.

The reasons for these modifications are discussed below.

Subroutine IOWAIT's function is to transmit synchronous (SYN) ASCII characters (ASCII character code 378; numbers subscripted by 8 in this report refer to octal, or base 8 , notation) to the terminal to prevent loss of output while the terminal is busy doing a previous instruction, such as a page erase. To perform this task it multiplies the ITIME (the only argument to subroutine IOWAIT) by the transmission baud rate divided by 10 and uses this number as the number of SYN characters to transmit to the terminal. (The SYN ASCII character is a no-op instruction for the terminal.) This method is at best inaccurate and at worst a tremendous unnecessary overhead on the system. Consider, for example, a call to IOWAIT with ITIME equal to 180 (such a call used to be made from HDCOPY). If a user is transmitting at 960 characters per second, then $180 * 960 / 10$ or 17,280 SYN characters were sent to the terminal - clearly a wasteful operation. By empirical determination it was found that a pause of 2 sec was sufficient for terminals during a page erase and $7 \mathrm{sec}$ was sufficient for terminals during a hardcopy operation. Therefore, in subroutines NEWPAG and ERASE the call to IOWAIT was replaced with a call to SLP with an argument of $2 \mathrm{sec}$, and in 
subroutine HDCOPY the call to IOWAIT was replaced with a call to SLP with an argument of $7 \mathrm{sec}$. Also, before the call to SLP in the above three subroutines, a call to the TCS subroutine TSEND is included to ensure beginning the terminal operation at the prescribed time. (Subroutine TSEND forces out to the terminal the internal TCS buffer.)

In order that the TCS software be initialized, a call to subroutine INITT with a single argument representing the terminal transmission baud rate (number of characters per second) is required. However, the transmission speed is known by the computer; how else could the computer communicate with a teletype? Therefore, a modification was made to subroutine INITT to have it call a function subprogram named ITRMBD. Subroutine ITRMBD accepts one argument, the job number, and it returns the value of the transmission baud rate. This frees the user from having to worry about this value, especially sinoe an application program usually is executed from many terminals with different transmission speeds. The user need only call INITT with an argument of 0 to have the transmission speed determined by subprogram ITRMBD. The above solution did not completely solve the problem of TCS internally determining transmission speeds. Numerous teletype lines are hardwired into the FED DC10 communications interface, which does not have the hardware/software to set transmission speed codes in the monitor table for a job connected to it. To alleviate this difficulty a program (SETSPD) was written to software-set the transmission speed codes of all the hardwired lines connected to the DC10. The program is run from the system AUTO file when the system is initialized. This program and the other subprograms mentioned in this section are discussed further in Sect. 6 . 


\section{TCS CHARACTER MANIPULATION SOFTWARE}

This section describes four machine-dependent subroutines for translating ASCII character strings required by the TCS software. Their names are constructs of the following mnemonics: convert, $\underline{K}$; left-justified ASCII one character per word, $\underline{A 1}$; to, 2 ; right-justified ASCII one character per word, $\underline{A S}$; left-justified ASCII five characters per word, AM. Therefore, to convert a left-justified ASCII text string to a right-justified array of characters in ASCII decimal equivalent (ADE) format, the appropriate subroutine to call would be KAM2AS. The next four subsections describe the argument list and calling sequence of subroutines KA12AS, KAM2AS, KAS2A1, and KAS2AM.

\section{1 SUBROUTINE KA12AS}

Subroutine KA12AS performs to Tektronix Terminal Control System specifications and may be used to convert left-justified ASCII characters (stored one character per word) into right-justified, zero-filled characters (stored one character per word). Calling sequence:

CALL KA12AS (NCHAR, KA1, KADE)

Argument 1ist:

NCHAR is the number of characters to be translated (unmodified by this subroutine).

KA 1 is the left-justified ASCII character array stored one character per word (unmodified by this subroutine).

KADE is the right-justified, zero-filled ASCII character array stored one character per word (returned by this subroutine). 
Required subroutines: None

Language: MACRO-10 (see Ref. 6)

Subprogram listing:

TITLE KA 12AS

$T 0=0$
$T 1=1$
$T 2=2$
$L=16$
$P=17$

ENTRY RA TLAS

SIXBIT /KA12AS/

KA 12AS： PUSH P,T2

HRRZ T2,eO(L)

JUMPE T2, BYEBYE

MOVN T2,T2

HRL T2,T2

HRRI T2,e2(L)

HRRZI T1,Q1(L)

LOOP: MOVE TO, (T 1$)$

LSH T0, -`D29

MOVEM TO, (T2)

AOJ T1,

AOBJN T2, LOOP

POP P,T2

BYEBYE : POPJ P,

; SAVE T2

;GET NUMBER TO TRANSLATE

;IS IT 0

;NO, MAKE IT NEGATIVE

;IN LEFT HALF

;NOW PUT IN THE OUTPUT ADDRESS

;GET ADDRESS OF A 1 CHARACTERS

;GET AN A1 CHARACTER

;MAKE IT ADE

IPUT THE ADE CHARACTER AWAY

; INCREMENT ADDRE33 FOR A1

;ARE WE FINISHED

; RESTORE T2

END

;WE ARE DONE

\subsection{SUBROUTINE KAM2AS}

Subroutine KAM2AS performs to Tektronix Terminal Control System specifications and may be used to convert left-justified ASCII

characters (stored five characters per word) into right-justified, zero-filled characters (stored one character per word). 


\section{Calling sequence:}

CALL KAM2AS (NCHAR, KAM, KADE)

Acgument list:

NCHAR is the number of characters to be translated (unmodified by this subroutine).

KAM is the left-justified ASCII character array stored five characters per word (unmodified by this subroutine).

KADE is the right-justified, zero-filled ASCII character array stored one character per word (returned by this subroutine).

Required subroutines: None

Language: MACRO-10

Subprogram listing:

TITLE KAM2AS

$\mathrm{TO}=0$

$\mathrm{T} 1=1$

$\mathrm{T} 2=2$

$\mathrm{L}=16$

$P=17$

ENTRY KAM2AS

SIXBIT /KAM2AS/

KAM2AS: PUSH P,T2 HRRZ T2,QO(L) JUMPE T2, BYEBYE

; SAVE T2 ;GET NUMBER TO TRANSLATE MOVN T2,T2 HRL T2, T2 HRRI T2,e2(L) HRR7T T1,01(L) HRLI T1,440700

LOOP: ILDB TO,T1 MOVEM TO,(T2) AOBJN T2, LOOP POP P,T2

BYEBYE : POPJ P, ;IS IT 0 ;NO, MAKE IT NEGATIVE ;IN LEFT HALF ;NOW PUT IN THE OUTPUT ADDRESS ;GET ADDRESS OF AM CHARACTERS ;GET A GOOD BYTE POINTER ;GET AN AM CHARACTER ;PUT THE ADE CHARACTER AWAY ;ARE WE FINISHED ; RESTORE T2 END ;WE ARE DONE 


\subsection{SUBROUTINE KAS2A 1}

Subroutine KAS2A1 performs to Tektronix Terminal Control System specifications and may be used to convert right-justified ASCII characters (stored one zero-filled character per word) into left-justified, blank-filled characters (stored one character per word).

\section{Calling sequence:}

CALL KAS2A 1 (NCHAR, KADE, KA1)

\section{Argument 1ist:}

NCHAH is the number of charaoters to be translated (unmodified by this subroutine).

KADE is the right-justified, zero-filled ASCII character array stored one character per word (unmodified by this subroutine).

KA1 is the left-.justified ASCII character array stored one character per word (returned by this subroutine).

Required subroutines: Norie

Language: MACRO-10

Subprogram listing:

TITLE KASEAI

$$
\begin{aligned}
& \mathrm{T} O=0 \\
& \mathrm{~T} 1=1 \\
& \mathrm{~T} 2=2 \\
& \mathrm{~L}=16 \\
& \mathrm{P}=17
\end{aligned}
$$

ENTRY KAS2A 1

$\begin{array}{lll}\text { SIXBIT } & \text { /KASZA1/ } \\ \text { KAS2A 1: } & \text { PUSH } & \text { P,T2 } \\ & \text { HRRZ } & \text { T2, } 20(\mathrm{~L}) \\ & \text { JUMPE } & \text { T2, BYEBYE } \\ & \text { MOVN } & \text { T2,T2 } \\ & \text { HRL } & \text { T2,T2 } \\ & \text { HRRI } & \text { T2, } 22(\mathrm{~L}) \\ & \text { HRRZI } & \text { T1, } 1 \text { (L) } \\ \text { LOOP: } & \text { MOVE } & \text { T0,(T1) }\end{array}$

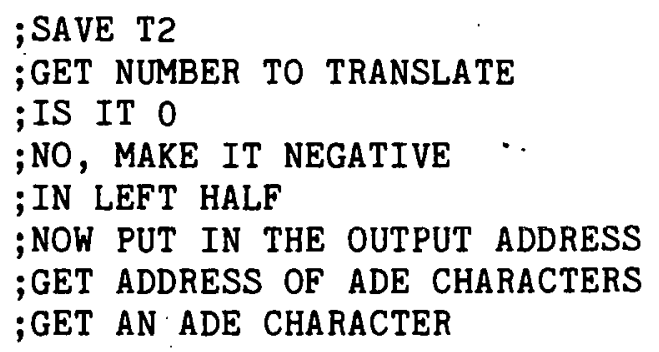




$\begin{array}{lll}\text { LSH } & \text { TO,^D29 } & \text {;MAKE IT A1 } \\ \text { MOVEM } & \text { T0,(T2) } & \text {;PUT THE A1 CHARACTER AWAY } \\ \text { AOJ } & \text { T1, } & \text {;INCREMENT ADDRESS FOR ADE } \\ \text { AOBJN } & \text { T2,LOOP } & \text {;ARE WE FINISHED } \\ \text { POP } & \text { P,T2 } & \text {;RESTORE T2 } \\ \text { POPJ } & \text { P, } & \text {;WE ARE DONE } \\ \text { END } & & \end{array}$

\subsection{SUBROUTINE KAS2AM}

Subroutine KAS2AM performs to Tektronix Terminal Control System specifications and may be used to convert right-justified ASCII characters (stored one zero-filled character per word) into left-justified, blank-filled characters (stored one character per word). Calling sequence:

CALL KAS2AM (NCHAR, KADE, KAM)

Argument list:

NCHAR is the number of characters to be translated (unmodified
by this subroutine).
KADE is the right-justified ASCII character array stored one
character per word (unmodified by this subroutine).
is the left-justified, blank-filled ASCII character array
stored five characters per word (returned by this
subroutine).

Required subroutines: None

Languagc: MACRO-10 
Subprogram listing:

\section{TITLE KAS2AM}

$$
\begin{aligned}
& \mathrm{TO}=0 \\
& \mathrm{~T} 1=1 \\
& \mathrm{~T} 2=2 \\
& \mathrm{~L}=16 \\
& \mathrm{P}=17
\end{aligned}
$$

ENTRY KAS2AM

$\begin{array}{lll}\text { SIXBIT } & \text { /KAS2AM/ } \\ \text { KAS2AM: } & \text { PU3H } & \mathrm{P}, \mathrm{T} 2 \\ & \text { HRRZ } & \mathrm{T} 2, \mathrm{QU}(\mathrm{L}) \\ & \text { JUMPE } & \mathrm{T} 2, \mathrm{BYEBYE} \\ & \text { MOVN } & \mathrm{T} 2, \mathrm{~T} 2 \\ & \text { HRL } & \mathrm{T} 2, \mathrm{~T} 2 \\ & \text { HRRI } & \mathrm{T} 2, \mathrm{e} 1(\mathrm{~L}) \\ & \text { HRRZI } & \mathrm{T} 1, \mathrm{e} 2(\mathrm{~L}) \\ & \text { HRLI } & \mathrm{T} 1,440700 \\ \text { LOOP: } & \text { MOVE } & \mathrm{T} 0,(\mathrm{~T} 2) \\ & \text { IDPB } & \mathrm{T} 0, \mathrm{~T} 1 \\ & \text { AOBJN } & \mathrm{T} 2, \mathrm{LOOP} \\ & \text { POP } & \mathrm{P}, \mathrm{T} 2 \\ \text { BYEBYE }: & \text { POPJ } & \mathrm{P}, \\ & \text { END } & \end{array}$

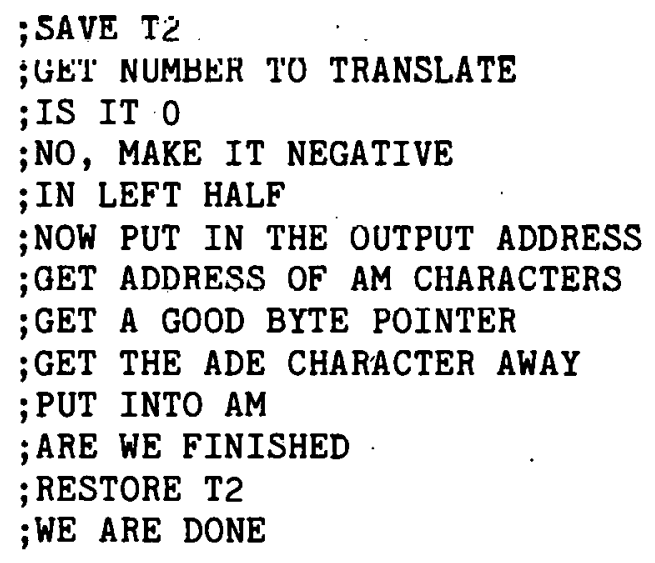




\section{TCS I/O SOFTWARE}

This section describes two subroutines for character transmission between a user application program and a Tektronix terminal. They are subroutines ADEIN and ADEOUT, which mnemonically represent ASCII decimal equivalent input and output, respectively. Both subroutines are written in MACRO-10; therefore, the TCS software library does not require the FORTRAN REAL TIME OPERATING SYSTEM 7 (FOROTS) to be in the user's high segment during execution.

\subsection{SUBROUTINE ADEIN}

Subroutine ADEIN performs to Tektronix Terminal Control System specifications and may be used to input right-justified, zero-filled ASCII characters from the user's terminal. The complete ASCII character set may be transmitted with this subroutine; however, there are certain characters which have a special meaning. These special characters are discussed below.

a) ${ }^{\wedge} \mathrm{U}$ If a ${ }^{\wedge} \mathrm{U}$ (ASCII character code 258; numbers which are subscripted by 8 in this report refer to octal, or base 8 , notation) is typed, the input line is erased and the input may be started over.

b) ${ }^{\wedge} R$. If a ${ }^{\wedge} R$ (ASCII character code $22_{8}$ ) is typed, the current line is retyped to the user's terminal for visual inspection of mistakes. The contents of the input buffer are not altered by this character.

c) (DEL) If a DEL (ASCII character code 1778) is typed, the previously input character is thrown away ard the terminal input line is backspaced one character. 
d) (BS) If a backspace (ASCII character code 108) is typed, it has the same effect as typing a DEL character.

e) (CR) If a carriage return (ASCII character code 158) is typed, it is ignored. (Remember on most terminals the carriage return key actually transmits two characters to a host computer - both a carriage return and a line feed.)

f) (LF) If a line feed (ASCII character code $12_{R}$ ) is typed, input is terminated without inserting the line feed character into the input buffer, and program control is passed back to the calling subroutine.

Remember - a maximum of 72 characters may be input by this subroutine during any single call.

\subsubsection{Further Considerations}

Tektronix 4010 series models have the capability of being used in the graphic input mode (GIN). When an ESC SUB character sequence (ASCII character codes $33_{8}$ and 328 , respectively) is transmitted to a terminal, the terminal's graphic cross-hair cursor will be turned on as a prompt for GIN mode input. By positioning the graphic cursor (using the thumb wheels located on the terminal) to a user-selected screen position and then striking a character, both the character (in ADE format) and four more characters are transmitted to subroutine ADEIN. The last four characters are decoded by the TCS software to locate the screen position of the graphic cursor.

Subroutine ADEIN is written to accept five and only five characters when the GIN mode switch is set; therefore, only a single character need be typed to transmit all the graphic cursor coordinate position 
information to the host computer. The other four characters are generated internally by the Tektronix terminal. This differs from previous implementations of the TCS software for the FED DECsystem-10, but it reflects the author's preference of execution.

One word of caution: do not strike the carriage return key while in the GIN mode. This will confuse the TCS software, since it expects to receive five characters instead of six under this circumstance. If a carriage return is struck during GIN mode input, unpredictable results will occur.

Calling sequence:

CALL ADEIN (NCHAR, KADE)

Argument list:

NCHAR is the number of characters to be translated (unmodified by this subroutine).

KADE is the right-justified ASCII character array stored one character per word (unmodified by this subroutine). Required subroutines: None Language: MACRO-10 
Subprogram listing:

\section{TITLE ADEIN \\ ENTRY ADEIN}

$T 0=0$
$T 1=1$
$T 2=2$
$L=16$
$P=17$

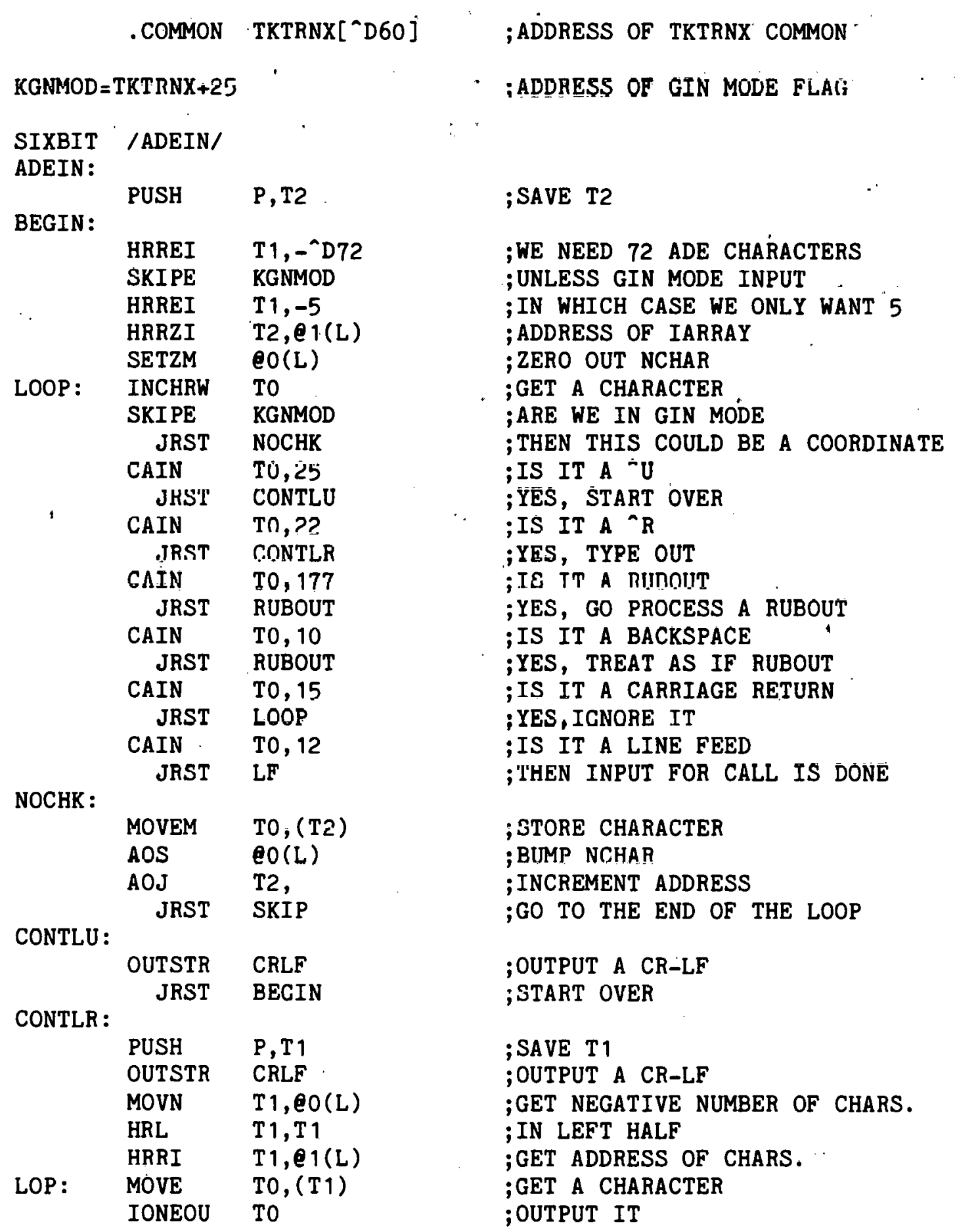




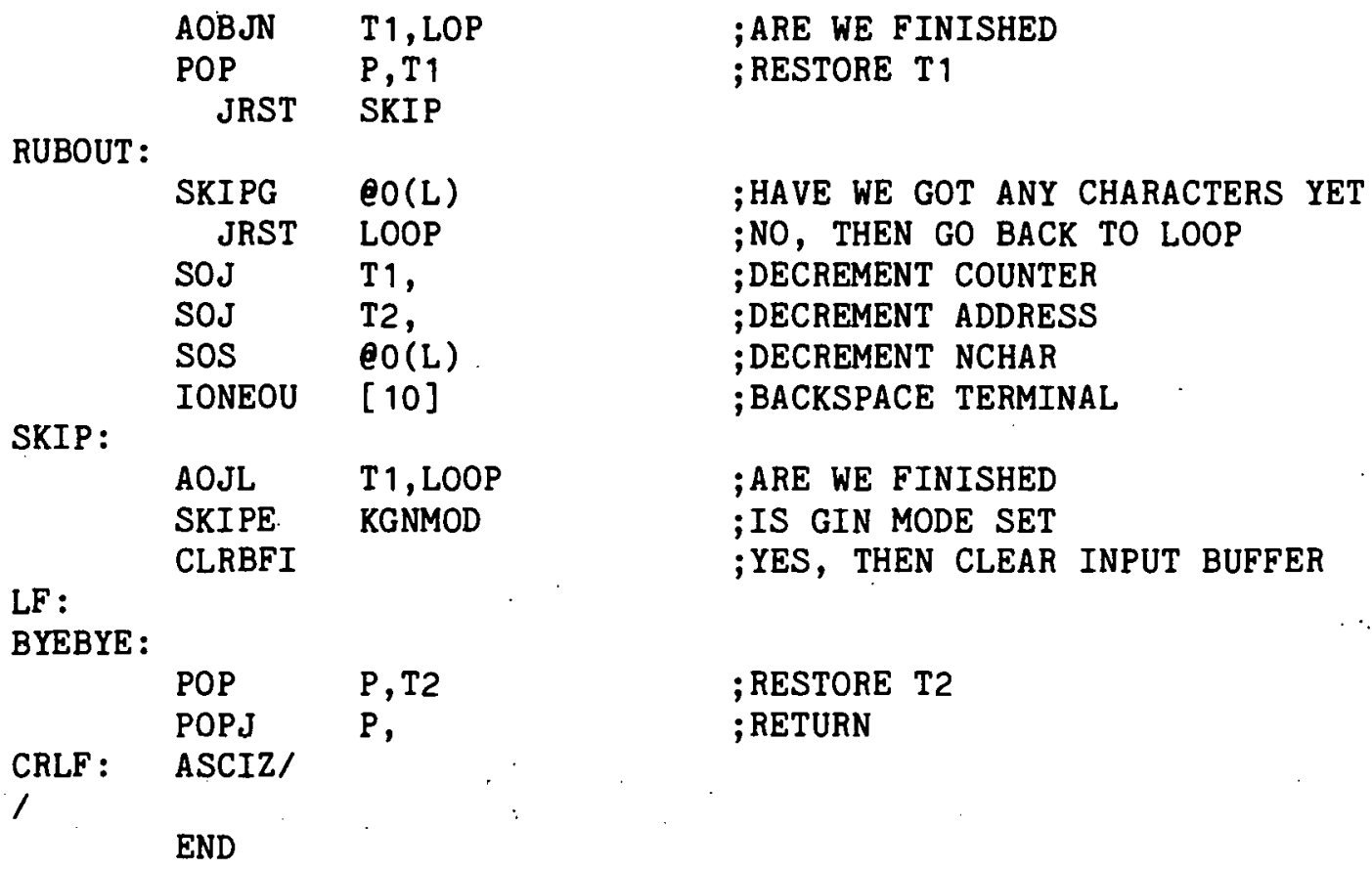

\subsection{SUBROUTINE ADEOUT}

Subroutine ADEOUT performs to Tektronix Terminal Control System specifications and may be used to output right-justified, zero-filled ASCII characters to the user's terminal. The complete ASCII character set may be transmitted with this subroutine because it uses the IONEOU machine instruction for output of a single Packed Image Mode (PIM) character. This instruction bypasses several monitor level checks; e.g., after every 72 characters, the monitor automatically inserts a carriage return-line feed sequence into the output stream. It is, therefore, an efficient way to transmit characters.

Calling sequence:

CALL ADEOUT (NCHAR, KADE)

Argument list:

NCHAR is the number of characters to be translated (unmodified by this subroutine).

KADE is the right-justified ASCII character array stored one 
character per word (unmodified by this subroutine).

Required subroutines: None

Language: MACRO-10

Subprogram listing:

$\begin{array}{ll}\text { TITLE } & \text { ADEOUT } \\ \text { ENTRY } & \text { ADEOUT }\end{array}$

$\mathrm{TO}=0$

$\mathrm{T} 1=1$

$\mathrm{L}=16$

$P=17$

$\begin{array}{lll}\text { SIXBIT } & \text { /ADEOUT/ } \\ \text { ADEOUT: } & & \\ & \text { MOVN } & \mathrm{T} 1, \text { CO(L) } \\ & \text { HRL } & \mathrm{T} 1, \mathrm{~T} 1 \\ & \text { HRRI } & \mathrm{T} 1, \mathrm{C} 1(\mathrm{~L}) \\ \text { LOOP: } & \text { MOVE } & \mathrm{T} 0,(\mathrm{~T} 1) \\ & \text { IONEOU } & \mathrm{T} 0, \\ & \text { AOBJN } & \mathrm{T} 1, \text { LOOP } \\ & \text { POPJ } & \mathrm{P}, \\ & \text { END } & \end{array}$

;GET NCHAR

; PUT IN LEFT HALF

;ADDRESS OF ADE CHARACTERS

;GET A CHARACTER

;OUTPUT IT

;ARE WE FINISHED

future considerations:

Since under the 603 a monitor buffered PIM I/O appears to be functioning correctly, 8 future system development of the TCS software library should consider replacing this subroutine with a subroutinc which uses buffered PIM output. 
6. TCS LOCAL SOFTWARE

This section presents two auxiliary subprograms and one program, which complete the TCS system software on the FED DECsystem-10. Program SETSPD is a privileged program which will set the transmission speed codes of teletypes connected to the DC 10 communications interface, integer function ITRMBD will return the transmission baud rate for any job number currently active in the system, and subroutine SLP will put the controlling job to sleep for a specified number of seconds.

\subsection{SUBROUTINE ITRMBD}

Subroutine ITRMBD may be used to return the transmission baud rate for a particular system job number. The baud rate is the number of characters per second being transmitted and received by the terminal. It is approximately the transmission speed in bits per second divided by ten.

\section{Calling sequence:}

IBAUD $=$ ITRMBD ( JOBNM )

Argument list:

JOBNM is the system job number for which the baud rate is to be obtained. If JOBMN is equal to -1 , then function ITRMBD returns the baud rate for the controlling terminal.

Required subroutines: None

Language: MACRO-10 
Subprogram listing:

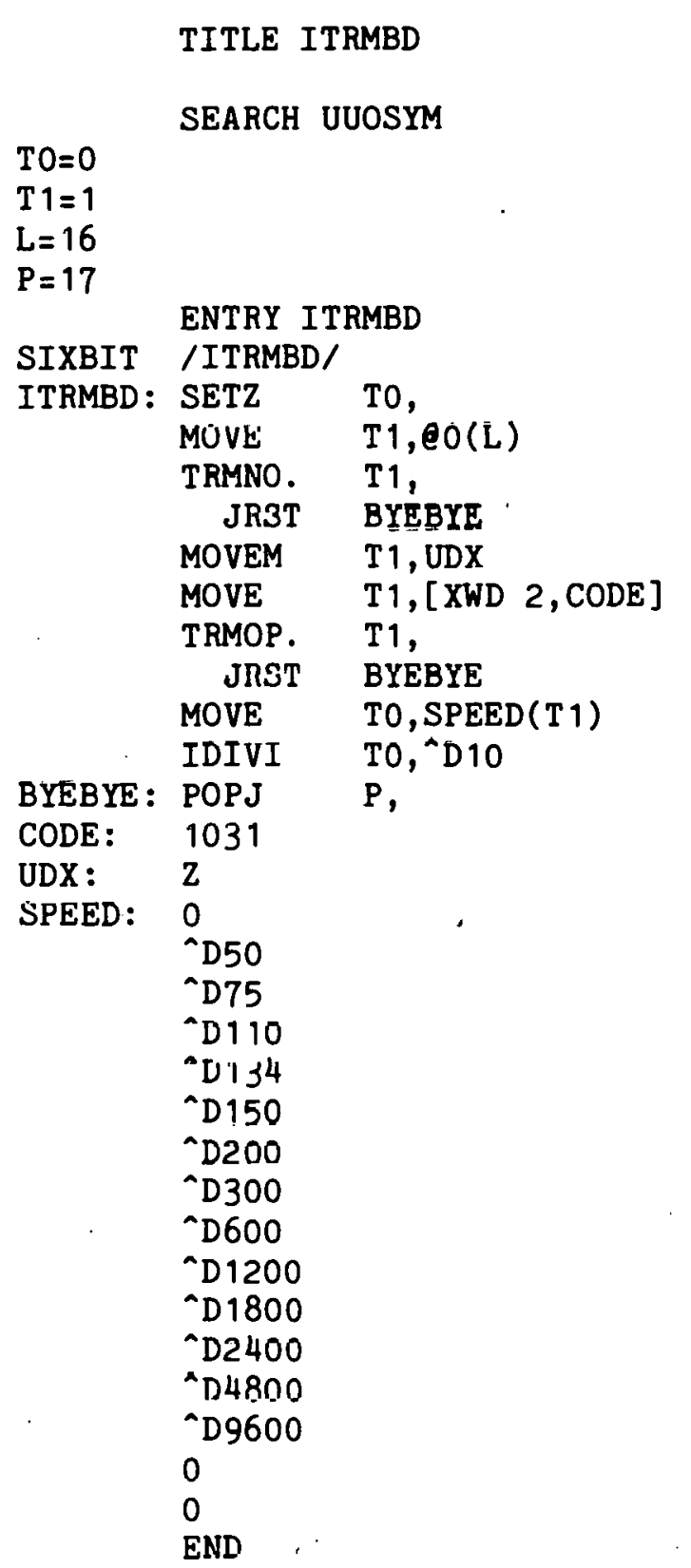

;CLEAR RETURN VALUE

;GET JOB NUMBER

;CFFIT IDBS UDX

;BUMMER

;STORE IN TRMOP BLOCK

;FORM TRMOP WORD

;DO IT

;ANOTHER POSSIBLE BUMMER .

;GOOD RETURN LOOKUP CORRECT SPEED ;CONVERT TO BAUD

;WE ARE DONE

;FUNCTION CODE FOR TRANSMIT SPEED 
6.2 PROGRAM SETSPD

Program SETSPD may be used to set the transmission speed code 9

(TSC) for any terminal connected to the FED computer system. This

program is intended to set the TSC of all hardwired terminals connected to the DC10 communications interface, since the DC10 cannot autobaud detect. The table named TABLE located under SUBTTL TTY-TABLE contains the TSC's and TTY line numbers which are set by this program.

Execution:

. R SETSPD

Restrictions:

In order for this program to perform correctly, it must be executed from a privileged project, programmer account.

Language: MACRO-10

Program listing:

TITLE SETSPD

SEARCH UUOSYM

. JBVER $=137$

VERNO=0 01

VEDIT $==2$

VMINOR $=0$

VWHO $==06$

;MA.IOR VERSION NUMBER ;MAJOR EDIT NUMBER

;MINOR EDIT NUMBER

;WHG LAST EDITOR

VSTSPD $==$ BYTE (3) VWHO (9)VERNO (6) VMINOR ( 18) VEDIT

LOC

. JBVER

VSTSPD

RELOC

$\mathrm{T} 1=1$

$\mathrm{T} 2=2$

$\mathrm{T} 3=3$

$\mathrm{T} 4=4$

$\mathrm{T} 5=5$

T $6=6$

$\mathrm{T} 7=7$

T $10=10$

$\mathrm{T} 11=11$

$\mathrm{L}=16$ 
$P=17$

SUBTTL THE-BIG-CODE

DEBUG :

SETSPD: JFCL

RESET

MOVE ' $P,[$ XWD PDLEN, PDLST]

MOVEI T1,NTBL ;GET NUMBER OF TTY'S TO SET

JUMPE T1,BYEBYE ;ARE THERE ANY?

MOVE T3,[XWD 3,SXCODE] ; YES, SET UP TRMOP FUNCTION

MOVN T1,T1 ;NELA'IH: NUMBER OF TTY'S

HRL TY,T 1 ;IN LEET HALF

HRRI T1,TABLE ;GET ADDRESS OF TTY TABLE

OUTSTR [ASCIZ/

HELLO, MY NAME IS SETSPD AND I AM GOING TO SET THE XMTSPEEDS

OF THE FOLLOWING TERMINALS WHICH ARE CONNECTED TO THE DC 10

/]

LOOP: MOVE T2,(T1)

HLRM T2, SPDCDE

HRRZ T2, T2

ADDI T2,.UXTRM

MOVEM T2,UDX

TRMOP. T3,

JR3T BAD

OUTSTK [ASCIZ/TTY/]

SUBI T2,.UXTRM

HRL T2,T?

PUSHJ P,OCTOUT

SPDOUT:

HLRZ T2, ( T 1)

PUSH $P, T$ I

MOVE T1,SPEED(T2)

OUTSTR [ASCIZ/ TO

PUSHJ P,DECOUT

POP P,T1

NITSTR [ASCIZ,

/]

BAD :

JRST CONT

OUTSTR [ASCIZ/?ERROR - YOU ARE NOT PRIVILEGED TO SET TTY/]

SUBI T2,.UXTRM

HRL $\quad T 2, T 2$

PUSHJ P,OCTOUT

JRST SPDOUT
;GET TTY SPEED CODE AND \# ; STORE SPEED CODE IN TRMOP BLOCK ;GET TTY \# ;MAKE IT A UNIVERSAL DEVICE INDEX ; PLACE IN TRMOP BLOCK ;SET IT

;GET TTY \# AGAIN

,MOVE TO LEFT HALF

;OUTPUT TTY \#
;GET SPEED CODE AGAIN ;SAVE T1

;GET SPEED IN CHARACIER3/SEC

/]

; TYPE II' OU'l'

; RESTORE T1 ;GET TTY NUMBER AGAIN ;MOVE TO LEF'I HALF ;OUTPUT TO TTY ;TYPE OUT SPEED

CONT :

AOBJN $\quad \mathrm{T} 1$, LOOP

BYEBYE :

EXIT 
SUBTTL SUBROUTINES

OCTOUT :

$\begin{array}{lll}\text { MOVE } & \text { T6,[POINT } 3, T 2] & \text {;POINTER TO T2 } \\ \text { SETZ } & \text { T5, } & \text {;SET NONZERO OUT FLAG } \\ \text { MOVEI } & \text { T4,6 } & \text {;ONLY 1/2 WORD WORTH } \\ \text { ILDB } & \text { T7,T6 } & \text {;GET OCTAL CHARACTER } \\ \text { SKIPN } & \text { T7 } & \text {;NONZERO? } \\ \text { JUMPE } & \text { T5,.+4 } & \text {;NO, HOW ABOUT NONZERO FLAG } \\ \text { ADDI } & \text { T7,60 } & \text {;MAKE IT ASCII } \\ \text { OUTCHR } & \text { T7 } & \text {;PRINT IT } \\ \text { SETO } & \text { T5, } & \text {;NONZERO FLAG ON } \\ \text { SOJG } & \text { T4,OCTLOP } & \text {;MORE CHARACTERS } \\ \text { SKIPN } & \text { T5 } & \text {;WAS IT O } \\ \text { OUTCHR } & {[" 0 "]} & \text {;TYPE IT OUT } \\ \text { POPJ } & \text { P, } & \text {; RETURN }\end{array}$

DECOUT :

$\begin{array}{ll}\text { IDIVI } & \mathrm{T} 1,12 \\ \text { HRLM } & \mathrm{T} 2,(\mathrm{P}) \\ \text { SKIPE } & 0, \mathrm{~T} 1 \\ \text { PUSHJ } & \mathrm{P}, \mathrm{DECOUT} \\ \text { HLRZ } & \mathrm{T} 1,(\mathrm{P}) \\ \text { ADDI } & \mathrm{T} 1, " 0 " \\ \text { OUTCHR } & \mathrm{T} 1 \\ \text { POPJ } & \mathrm{P}, \\ \text { SUBTTL } & \text { TTY-TABLE }\end{array}$

;DIVIDE BY 10 ;SAVE REMAINDER

;SEE IF ANYTHING LEFT

;YES, GO BACK

;GET DIGIT BACK

;MAKE IT ASCII

;TYPE IT

;LOOP BACK UNTIL DONE

REPEAT $0,<$

THE FOLLOWING LIST CONTAINS THE XMTSPEED CODE AND TERMINAL LINE NUMBER IN HALF WORD FORMAT FOR ALL THE TERMINALS WHOSE XMTSPEEDS ARE NOT SET BY HARDWARE; I.E., THE LINES CONNECTED TO THE DC 10.

LEFT HALF CONTAINS THE XMTSPEED CODE

RIGHT HALF CONTAIN3 THE TTY \#

THE TRANSMISSION CODE IS LISTED BELOW

CODE CHARACTERS PER SEC

$0 \quad 0$

$1 \quad 50$

$2 \quad 75$

$3 \quad 110$

$4 \quad 134$

$5 \quad 150$

$6 \quad 200$

$7 \quad 300$

$10 \cdot 600$

$11 \quad 1200$

$12 \quad 1800$

132400

$14 \quad 4800$

$15 \quad 9600$

16 EXTERNAL A 
FOR EXAMPLE, SUPPOSE THE DC10 IS TRANSMITTING TO TTY 1 AT 4800 CPS. THEN THE CORRESPONDING ENTRY IN TABLE WOULD BE

$14,, 1$

$>$

TABLE :

11,0

$15,, 2$

$11,, 12$

$11,, 16$

NTBL $=-$ TABLE

SXCODE : 2031

UDX : $\quad Z$

SPDCDE: $Z$

SPEED: 0

D50

D75

D110

D134

D 150

D200

D300

'D6חก

n1200

D1800

D2400

D4800

D9600

0

0

PDLST : $\quad 0$, , PDERR

BLOCK 100

PDLEN $=$ - - HDLST

PDERR: ASCIZ/?PDI. NỤFRFLOW

$$
\text { I }
$$

END
;TTY 1 XMTSPEED OF 4800 CPS

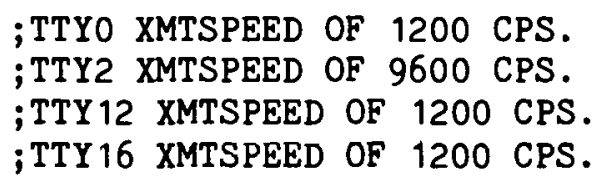

;CODE TO SET SPEED

\subsection{SUBROUTINE SLP}

Subroutine SLP may be used to put a program to sleep for a specified number of seconds. This subroutine has been substituted for subroutine IOWAIT in the TCS subroutines HDCOPY, NEWPAG, and ERASE. The reason for this substitution was discussed in the system considerations section of this report. 


\section{Calling sequence:}

CALL SLP (ISEC)

Argument list:

ISEC is the number of seconds to sleep.

Required subroutines: None

Language: MACRO-10

Subprogram listing:

$\begin{array}{ll}\text { TITLE } & \text { SLP } \\ \text { ENTRY } & \text { SLP }\end{array}$

$\mathrm{TO}=0$

$\mathrm{L}=16$

$P=17$

$\begin{array}{lll}\text { SIXBIT } & \text { /SLP/ } & \\ \text { SLP: } & & \\ & \text { MOVE } & \text { TO, OO(L) } \\ & \text { SLEEP } & \text { TO, } \\ & \text { POPJ } & \text { P, }\end{array}$

END

; NUMBER OF SECONDS TO SLEEP ;GOOD NIGHT

;GOOD MORNING 
7. CONCLUSIONS

Hopefully, this report will sufficiently document the FED system dependencies of the TCS software in order that future updates to this software product will be upwards compatible, thus ensuring system continuity between user application programs. 


\section{ACKNOWLEDGMENTS}

I would like to express my appreciation to C. L. Thompson for his comments on the internal operation of the TCS software, K. H. Carpenter for his suggestion to use PIM output in subroutine ADEOUT, to R. D. Burris for his patience in helping me debug MACRO subroutines, and to D. W. Swain for his empirical determination of the delay time for a Tektronix hardcopy unit. 


\section{REFERENCES}

1. H. A. Kamel and M. W. McCabe, "The GIFTS System: Version 4B User's Manual," University of Arizona, Tucson, Arizona (March 1978).

2. "Tektronix PLOT 10 Terminal Control System User Manual," Tektronix, Inc., Beaverton, Oregon (February 1977).

3. "Tektronix PLOT 10 Terminal Control System System Manual," Tektronix, Inc., Beaverton, Oregon (February 1977):

4. "Tektronix PLOT 10 Terminal Control System Installation Guide," Tektronix, Inc., Beaverton, Oregon (February 1977).

5. "Tektronix PLOT 10 Terminal Control System Verification Routine," Tektronix, Inc., Beaverton, Oregon (February 1977).

6. "DECsystem-10 MACRO Assembler Reference Manual," Digital Equipment Corporation, Maynard, Massachusetts (April 1978).

7. Appendix D in "DECsystem-10 FORTRAN Programmer's Reference Manual," Digital Equipment Corporation, Maynard, Massachusetts (June 1977).

8. C. L. Thompson, private communication (April 1979).

9. "DECsystem-10 Monitor Calls Manual," Digital Equipment Corporation, Maynard, Massachusetts (January 1978). 
ORNL/TM-6918

Dist. Category UC-20

INTERNAL DISTRIBUTION

1. F. W. Baity

2. J. K. Ballou

3. S. C. Bates

4. R. D. Burris

5. W. D. Cain

6. J. D. Callen

7. K. H. Carpenter

8. L. A. Charlton

9. B. A. Clark

10. D. N. Clark

11. W. K. Dagenhart

12. L. Deleanu

13. K. N. Fischer

14. R. H. Fowler

15. P. Gaffney

16. J. C. Glowienka

17-36. W. H. Gray

37. G. R. Haste

38. T. C. Jernigan

39. P. W. King

40. C. E. Knight, Jr.

41. E. A. Lazarus

42. C. J. Long
43. M. S. Lubell

44. R. W. McGaffey

45. 0. B. Morgan

46. J. K. Munro, Jr.

47. A. P. Navarro

48. G. H. Neilson

49. D. R. Overbey

50. C. E. Parker

51. J. K. Penny

52. J. Sheffield

53. K. A. Stewart

54. W. C. T. Stoddart

55. D. W. Swain

56. P. L. Walstrom

57. W. R. Wing

58-59. Laboratory Records Department

60-61. Central Research Library

62. Document Reference Section

63. Laboratory Records, ORNL-RC

64. ORNL Patent Office

65. Fusion Energy Division Library

66. Fusion Energy Division

Communications Center

\section{EXTERNAL DISTRIBUTION}

67. D. J. Anthony, General Electric Company, Building 23, Room 290, 1 River Road, Schenectady, NY 12345

68. R. W. Conn, Department of Nuclear Engineering, University of Wisconsin, Madison, WI 53706

69. H. K. Forsen, Exxon Nuclear Company, Inc., 777 106th Avenue, N.E., Bellevue, WA 98004

70. H. P. Furth, Princeton Plasma Physics Laboratory, Princeton University, P.0. Box 451, Princeton, NJ 08540

71. R. W. Gould, Building 116-81, California Institute of Technology, Pasadena, CA 91109

72. R. L. Hirsch, Exxon Research and Engineering Company, P.0. Box 101, Florham Park, NJ 07101

73. Office of Assistant Manager, Energy Research and Development, Department of Energy, Oak Ridge Operations Office, Oak Ridge, TN 37830

74-195. Given distribution as shown in TID-4500, Magnetic Fusion Energy (Distribution Category UC-20) 